\title{
Professionalization in Universities and European
}

\section{Convergence}

\author{
AMPARO JIMENEZ VIVAS and DAVID MENENDEZ ALVAREZ HEVIA
}

\begin{abstract}
The constant assessment of the quality of higher education within the framework of European convergence is a challenge for all those universities that wish their degrees and diplomas to reflect a unified Europe. As is the case in any assessment, change and review process, the quest to improve quality implies measuring achievement of the objectives set, which in turn means defining the most relevant functions shared by universities. One of the many functions that a university fulfils in society is enabling university students to take up certain occupations. Thus, analyzing the employment pattern of a university's graduates and identifying their competences becomes an indicator of the quality of the education provided by that university and, hence, one of the bases on which degrees are defined within the European Higher Education Area.
\end{abstract}

\section{Good-quality Higher Education and the Employment Obtained by University Graduates}

The political, economic, demographic and technological changes that have occurred in Europe over recent years have had an impact on universities and led to significant changes in academic life. Spain has been affected by this process of European convergence, as it adhered to the Bologna Declaration right from the start and has taken clear steps to ensure that it is fully involved in the European convergence. In taking a brief look back at the past to help us understand the current situation and the ongoing relationship between universities and the socio-occupational environment, it is important to highlight some decisive turning points:

1. The perception of university as a place for preserving and developing knowledge and transmitting it to a small number of privileged people began to change radically in the 1960s, when there was a considerable increase in demand for higher education, leading to what has been called 'university for the masses'. To a certain extent this situation, which occurred in the more developed countries, took many universities by surprise: they were forced to deal with a quantitative and, in some respects, qualitative shift without having made the necessary changes to their old structures and methods (Izquierdo and González, 1994). This period saw the emergence of some considerable concern about the sociooccupational integration of university graduates. Studies and research indicated that universities needed to concern themselves with training professionals who could, with some guarantee of success, enter a socio-occupational environment which, in the case of Spain and particularly during the period 1976-1985, was suffering from a serious economic recession and a major employment crisis. The labour market was beginning to be characterized by significant levels of unemployment and profound processes of structural change, such as feminization, a later age of entry to the labour market, rising educational levels and changes in employment structures (Cuadrado and Iglesias, 2003, p. 37). 
2. In the 1980s, several countries, including Spain, introduced new legal frameworks, a notable feature of which was the recognition that universities had to be autonomous if they were to achieve their objectives of quality and progress. It was believed that this autonomy would enable universities to innovate, become more efficient and enhance their effectiveness. With regard to the sociooccupational environment in Spain, the period 1985- 1992 saw a significant increase in economic activity (with 1.7 million jobs being created) but in 1992 a new crisis led to a slowing of both economic activity and job growth. In 1994, unemployment reached an all-time high of 24 per cent, with 3.7 million people unemployed. In addition, the abolition of borders with Europe brought Spanish markets into contact with the rest of the EU, significantly affecting competitiveness. This trend in the European labour market highlighted the changes that had occurred over a very short period. A new employment landscape was beginning to emerge, dominated by temporary and fixed-term contracts, variable working hours, part-time work, high rates of unemployment, etc., in contrast with the more traditional features that had previously characterized the market, such as the predominance of permanent contracts, full-time work and low unemployment rates. According to Latiesa et al. (2001), the new conditions on the labour market were the result of a combination of several fundamental changes, such as the globalization of markets, the introduction and development of new technologies, the emergence of new professions, the consolidation of a mass consumer society, cultural changes and the new ways of life emerging in modern society.

3. In the early 1990s, a series of events associated with the desire to provide efficient, goodquality university education led to an experimental assessment programme to assess the quality of the university system; sixteen universities took part in this programme. In 1994-95, a European pilot project to assess the quality of higher education was conducted, giving rise to the Spanish Plan Nacional de Evaluación [National Assessment Plan] to assess the quality of Spain's universities. It was during this period that the phrase 'quality of teaching', particularly in higher education, began to appear not just in education theory and practice but also in legislative proposals (Ruiz and Molero, 2002). People began to speak of the quality of university education as a complicated concept that was difficult to define and even more difficult to assess. Even the Consejo de Universidades [Universities' Council] (2002) said the concept of quality in higher education was difficult to define and could be perceived in different ways, depending on the observer's viewpoint. The various interested parties had different, but equally valid, interpretations of quality. Despite this problem, the concept, its main features and factors, and its implications needed to be clarified. It was a challenge that had to be met because higher education institutions were subject to an ongoing process of assessment and improvement by the wider sphere of which they were part. The vagueness and complexity of the concept meant that increasing consensus was granted to the thesis that the quality of university education has to be seen as a relative and multi-dimensional construct in relation to the objectives and stakeholders in the university system. This means that the following dimensions and aspects must all be taken into account if the quality-assessment process is to be successful (Consejo de Universidades, 2002):

- efficiency and effectiveness of investment in higher education;

- compliance with international quality standards in training programmes that

allow for international competitiveness and mobility;

- meeting society's education and training needs;

- providing the graduates that society needs. 
The overall concept of teaching quality proposed by Izquierdo and González (1994) suggests that other components contributing to total quality must also be considered:

- quality of the study plan: this is the interface between society's requirements and what happens, in terms of its educational work, within a teaching establishment; to a certain extent, it is also the interface between the present and the future, if we take account of the fact that the study plan establishes, orshould establish, the prerequisites (based on the current social, occupational and scientific contexts) for training people who will need to integrate themselves into society in future years;

- quality of the teaching/learning process: the quality of the process can be defined as the degree to which the objectives set are achieved by that process;

- quality of integration: this focuses on how graduates react to society. Graduates should achieve a higher level here insofar as it is easier for them to attain the professional skills and abilities and level of personal development considered essential to perform successfully those activities most characteristically associated with the functions commonly attributed to graduates in the corresponding social environment;

- quality of service and of medium- and long-term results: this refers to the extent to which graduates as a whole meet society's needs in their specific areas of activity and achieve their own personal development. Usually, after completing their studies, graduates undergo a process of integration, during which they receive further training from enterprises or other employers, or on their own initiative. This variable needs to be considered in any overall analysis of quality. It may be, for example, that some graduates have a high level of professional and social development, which will lead to a very high assessment of service quality, when this is actually not a result of the training received in the university institution but rather of a costly process of integration. It is clear that the employment achieved by graduates has now become an essential criterion when assessing the quality of universities.

4. Since 1998 and the Sorbonne Declaration, a process has been launched in Europe to promote the convergence of national higher education systems. In this respect, the Conference of Spanish University Rectors, in accordance with the General Assembly held on 8 July 2002, supported the principles set out in the Bologna Declaration and the establishment of a European Higher Education Area. As part of this process, summer 2000 saw the launching of a pilot project called "Tuning Educational Structures in Europe" (coordinated by the universities of Deusto in Spain and Groningen in the Netherlands), whose purpose is to harmonize education structures in Europe - that is, to establish a system of recognisable, comparable degrees and diplomas.

This study has provided in-depth knowledge of the situation of education in Europe. It has also led to some important conclusions regarding education studies in Europe, including the following:

- there is a wide variety of good quality degrees and diplomas in the field of education in the sixteen countries studied;

- analysis of professional profiles and course content leads to the identification of eleven academic areas covered by these degrees and diplomas: educational guidance; technology and the media; health education; training in organizations; teaching children; didactic specialization; management of educational institutions; specialized education; continuing and adult education; special educational needs; community development; 
- in-depth analysis of these areas enables us to identify four main types of degrees and diplomas in education in Europe: degrees and diplomas in teaching and education sciences; degrees and diplomas in social/specialized education; degrees and diplomas in special education/teaching; degrees and diplomas in socio-cultural facilitation and community development;

- in terms of professional openings, these are more clearly defined in the socio-educational areas of specialized social education and socio-cultural facilitation and community development than they are in the more strictly educational fields (education sciences and special education);

- lastly, this study has also enabled us to identify the emergence of new professional profiles in the field of education which are being widely acknowledged, are in demand and provide excellent professional prospects (e.g. education mediator, community teacher, children's teacher, 'train the trainer' posts, etc.).

\section{Rapprochement between Universities and Labour Market}

Nowadays we can assert that socio-professional placement is a transcendental issue for young people, enterprises, universities and society in general (Ruiz and Molero, 2002). The flexibility of the labour market, the economic and demographic development of technology, together with the democratization of universities and the enhancement of other formative opportunities have as a consequence, a concern when searching for an appropriate job related to the qualification obtained by the jobseeker. The increasing problems of unemployment and inadequate working conditions, affect a big group of the population, including university graduates (although they are a minor proportion compared with other less qualified groups), with subsequent debate about the duties assigned to the education system and the role that universities should play in society. Thereby the vocational purpose of university is in question and so are the methods used to obtain it (Martinez, 2002).

These interests will not decrease, quite the contrary, they will be more important in the near future. Therefore, it is important to have at our disposal, systematic and rigorous information about the process of socio-occupational placement of university graduates as much as to improve these institutions as a response to social demands (Ruiz and Molero, 2002). After analyzing the universities' objectives it is patently obvious that one of their main functions is the vocational training of graduates. As previously asserted, the excellence rating of a higher education institution depends on the achievement of its objectives and at the same time, on adapting these objectives to a determined context. At any given moment the work placement of graduates in the labour force will be one of the quality standards for universities.

The different researches related to the topic place an emphasis on viewing labour placement as a factor to consider in the process of improving and reforming universities. In this way, the analysis of the socio-professional job placement of the graduates is seen as an effective method to obtain better quality standards for higher education. The analysis of labour placement will be useful for the evaluation of the quality of development in university; it will also be useful for the quality accreditation process. It will act as a tool to provide this information to the university community and other related collectivities. Thus the analysis of the labour placement affects all areas involved in the university education process, in the following ways:

- As an accreditation of the university itself by means of evaluation of quality, it will be improving: study plans; teaching methodology; management structure; education

- adequate training for employment demand; decision-making. 
- For the clients' gain and as a foundation for universities.

- As achieving of necessary information to guide career development of students.

- To guide the labour policies of legislators and politicians.

- To make the enterprises aware of existing professional profiles and to be able to meet their demands.

- To society in general as a contribution to the cost-effectiveness of the population's human resources and to satisfy the demand of properly trained professionals.

Students, responsible undergraduates, and external agents have, as a common goal, the idea of a university which facilitates the transition from university to a job placement.Obviously, a satisfactory transition carries more things than the simple search for a job. It seems that the expectation of university students of finding a job related to the training they have received (at university) is coherent, hence, in the study of their socio-professional placement, we can investigate whether it is possible to be over-qualified and also whether the cause of the position's category corresponds to the academic levels obtained and if the duties required correspond to the capacities and skills that the students have been trained for. Also, just like the majority of the experts in the aforementioned area, the indicator of membership should be the insertion without taking into consideration the other factors which affect the transition from university into the working world. At the same time, the valuation of the process of graduate placement cannot be carried out if we consider the placement exclusively as an indicator of the extrinsic quality of a university. It is necessary to consider both, this placement and the different elements that could be affecting it. As previously explained, the quality of university studies should be understood as a multidimensional concept that should be appreciated as a function of the institution's circumstances, and also of the social-context in which it finds itself. Hence we can not exclusively consider the placement; we also have to consider the internal and external factors that can affect it (Molero, 2000). Two aspects have been considered by Molero (2000): the first refers to the studies carried out by graduates and the second is based on the job placement process. If we want to know the opinion of graduates regarding their training we should focus on the following points:

- Be aware of the image that graduates have of their entire university once they have finished their studies.

- Establish the training and continuing training requirements.

We should be aware of the job placement process adhering to these points:

- We should be aware of the status of placement.

- Approach the theory and practice evaluation provided in relation to the job once it has been developed.

- Evaluation of incidents in the work status during the final year at university.

- Know the job placement difficulties in concrete professional areas for the group of unemployed graduates or graduates who are working in places that are not related to their area (Molero, 2000). 
One of the dimensions of institutional evaluation (Consejo de Universidades, 2002) is the academic results that should be analyzed throughout a long-term period by means of the following points:

- Employment and demand of graduates with this qualification and its social image.

- Ratio of first-job graduates working in placements that are related to their training.

- Opinions of graduates with regard to their training as soon as they look for a job

and/or find it.

- Opinions of employers with regard to the training in the initial stage of job search

and, indeed, once they have been successful in doing so.

- Evaluate the adjustments between the profiles of the qualification and the characteristics

of the graduates.

Therefore, it is important to dispose of systematic and rigorous information about the job placement processes of graduates and also their opinions about their training with regard to these processes. In spite of the great number of studies published during the last decades on this topic, the complexity when analyzing the socio-professional placement of graduates and the necessity to tackle the process from different discipline perspectives has exposed an absence of data on the destination of graduates with different types and/or level of qualifications as one of the main concerns of most higher education institutions. It is common to find academic units that place a lot of importance on the job placement of their graduates both in quantitative (number of graduates working) and quantitative (quality of job) terms, although, in some disciplines they do not monitor their progression and thus, the final result of the training is not known. In any case, there is reason to consider the training given to students as a key point in their employability and it is also worth highlighting the usefulness of their preparation. With regard to the job placement of graduates we do not have much data at our disposal to make categorical affirmations, but this varies depending on the qualification. As an improvement, some universities have proposed to elaborate on the system by collecting feedback from their graduates. Others have delved further into developing and improving this area, by establishing strategies to relate activities with the actual work placement of graduates. Some examples of these activities are: the establishment of employment opportunities, providing practical experience in a working environment, creation of work skill courses, promotion of career counselling services, and the organization of new postgraduate studies, etc. According to this, it would be logical to think that the production of graduates, in their amount and typology (different professional fields), should be determined by the socioeconomic requirements of the society that finances their training. Hence, the access to university education, of different degree subjects should respond to a hard model of supply and demand. However, a discussion exists about intensity and linearity with regard to the relation between university and enterprise. The difficulty arises because we live in a changeable and volatile environment, where changes produced in the labour market make the full adaptation of university degrees to these demands impossible. The reason for this is the higher velocity of change in the labour market that makes the full adaptation of university degrees impossible in their revision of study plans, teaching methodology and university structure, amongst others. Legal and administrative systems from most European countries only grant partial autonomy to higher education institutions. On the one hand, these institutions are managed by their academic ideals; on the other hand they are constantly impeded by a combination of external pressures and interventions in favour of professional purpose and demands of the labour market. Discrepancies between university and employment arise from these tensions and changes. University is usually seen by the universityrepresentative as an 
institution pressured by external agents to change. Nevertheless, it is true that the educational system in general, including higher educational institutions, should not solely think in terms of productive demands but should also look for the personal development of its students. Education must be more than simply the means of access to a job; it must also provide students with life-long skills (Martinez, 2002). At the same time, higher education tends to be linked less to occupational duties than other levels of training leading to professional practice. This is due to the fact that a variety of skills and techniques which develop the selflearning capacities, problem solving and critical reflection are required. This cannot be directly provided by university education. Undergraduates should not just be trained for present requirements but should also be prepared to anticipate and propose innovations.

The Higher Education and Labour Market survey (Brennan and McGeevor, 1987) showed that higher education provides a number of advantages in areas such as critical thinking, independence, work organization, application of knowledge and attitudes, writing expression and self-confidence. In short the study considers a number of worthy transferable aptitudes, and the level of attainment that should be considered, in order to provide a critical evaluation of the different degrees, because they constitute fundamental elements of traditional higher educational values. It would be convenient for institutions to set their objectives with regard to the development of aptitudes and individual skills, and later evaluate the fulfilment of previous objectives. In 1987 Brennan and McGeevor claimed that higher education creates and supports what is denominated as a "critical reasoning culture" which constitutes the base of modern society's technical and humanistic understanding. The author believes this culture can be transmitted not only by higher education despite university being the main source of reinforcement and foundation of this culture. The author claims that:

...a higher educational system concerned with fulfilling the immediate demands created by economy, in order to avoid possible critical enquires, fails in its own duty to economy, meaning, the transmission of culture. The characteristics of thinking and expression that are located at the base of this culture constitute a requirement of occupational roles. All higher education institutions take part, but the ones that contribute the most to the expansion net of influences and the expansion of the skill pool are the ones that make efforts to show this culture to new groups (Brennan and McGeevor, 1987, p. 76).

Complaints about the contrast between university and reality have been the proposed focus of a huge orientation of employment demands, but these requirements are not clearly defined and we need a period of time so that graduates from the degree in demand are fully qualified. Even if University was transformed to have adaptation to the market as its main objective, there would be imperfections in regard to keeping up with the capacity of future demand. Therefore, university should include specialized education to better facilitate stability and promotion possibilities with enough general training to permit graduates to adapt to their work placement. These days, most of the researchers and experts still maintain the opinion that University graduates have more qualitative and quantitative potential of placement in the labour market than people with other qualifications. Though their sociolabourer insertion depends on many factors, unemployment and unstable employment are problems that affect this sector of the population. In reality, the elevated number of graduates and the limited number of job positions open to their qualifications creates job competition and in turn the increase of accumulative qualifications and other demands like professional experience, languages, IT, PhD, courses, etc.

Formative profiles should be studied to discover whether an excess of qualification exists and if so, whether it is a response to the competitive labour market, caused by deficits and lacks of university education or because of a change of perception of education as a continuous process that does not start and finish in University (Figuera, 1996). One way of finding out is to research what the students 
themselves think about the complementary training with regard to these issues. However, evaluating the tendencies of extending the curriculum with courses and other educative activities like overqualification can be an error. It seems like a substitution, to make up for skills the student will find in the labour market. When the quantity of employment offers increases, students naturally lose motivation to complete their studies. The result of high rates of inadequate working conditions and exploitative employment, for many highly qualified graduates, is the existence of high levels of overqualification for the specific job, which would not exist if jobs were to be allotted according to levels of qualification (Figuera, 1996).

The market of a society that evolves with such rapidity requires new skills in its workers. To avoid the idea of a university which offers an overly generalized training, insufficient practice, and that does not adapt to the exigencies of job positions, it is required to train flexible, autonomous and enterprising graduates. The market, therefore, needs active agents for change and this is the best way for the university to intellectually influence forces in the labour world.

The quality challenge will only be possible if the research community accept the product transformations and adapt university to these changes that can be briefed in a new organization of knowledge and better control. Professional profiles do not have to coincide with academic profiles and systems which have more adaptive value and that are more than strictly specialized programmes are needed. The curriculum required for society needs the cooperation of different academic fields with agile and flexible structures.

It is convenient for young people who are considering their future to receive as much information about the possible consequences of their decisions as possible. It is important to think on the one hand, about the general characteristics and current market changes and on the other hand to think about which ones require the skills and competences that this market demands that the current climate foresees over the coming years.

\section{Some Conclusions}

As can be seen, a university education adapted to the socio-occupational environment is not the sole requirement nowadays; degree-level studies are also being designed around professional profiles, with the latter determining the competencies to be acquired and the course content to be developed. The first tool to be used in defining clearly and realistically which professional profiles should be considered, so as to obtain a systematic and rigorous analysis of the current situation, must be studies of the employment obtained by graduates. The use of various graduate employment studies to gain an awareness of professional profiles is a vital first step that will enable us to identify the combination of competencies required to ensure that the individual is suited to the job and vice versa. This is a subject being researched by numerous institutions and researchers. It is impossible to provide an exhaustive list, but we should like to mention just some of the contributions that touch on the complexity and significance of this subject:

- Figuera (1996) identifies the various stages through which university graduates pass in tackling the challenge of employment, and the various patterns of sociooccupational integration;

- the Grupo de Referencia de Evaluacion Technica (Technical Evaluation Reference Group) group (Casal et al., 1991) points to the existence of different routes (identifying six in particular) university graduates take in obtaining employment; 
- García Montalvo et al. (2003) take an in-depth look at the job-hunting process and the matching of job specifications and graduates' personal qualities;

- Rodríguez and Prades (2003), Cabrera et al. (2003) group surveys of university graduates into different categories;

- several Spanish universities (Rovira i Virgili, Navarra, Santiago de Compostela, Girona, Autónoma de Barcelona, Pontificia de Salamanca, Universidad de Salamanca, Complutense) have also conducted various studies on this subject;

- mention should also be made of the work done by the Universidad de León (coordinated by Javier Vidal García), which, in 2003, held a seminar on methods of analyzing graduate employment, during which various speakers and working groups analyzed the situation with contributions from both European and North American experts (Vidal García, 2003);

- ANECA (Agencia Nacional de Evaluación de la Calidad y Acreditación [National Quality-Assessment and Accreditation Agency]) (2004a, 2004b) conducted a study on human-resources officers in enterprises operating in Spain. This was included in the broader framework of the "encuesta de inserción laboral, estudio sobre el ajuste entre la Universidad y el Mercado Laboral" [integration into working life: study of the relationship between university and the labour market], which comprised three major national surveys: one of university graduates in the year 2000, one of university students, and the ANECA one of employers. In brief, the aim of the study was to find out what enterprises thought of the training received at university by graduates they had recently taken on and which aspects of that training they felt could be improved, with a view to ensuring that university education met the real needs and requirements of the labour market;

- at the same time, the Kassel University in Germany and researchers such as Brenan and others in the UK have been conducting long-term studies of this kind, with a view to identifying trends in Western Europe;

- at European level, it is worth mentioning the Careers after Higher Education: a European Research Study (CHEERS), CHEERS Project, which aims to measure the results of higher-education studies by graduates' level of success in the world of work, and, from a different perspective, the Tuning Project (2003) (González and Wagenaar, 2006) set up by universities to respond to the challenge set by the Bologna Declaration and which has had a huge impact. From all of this, we can conclude that both universities and the way in which work is organized are changing to relate better to each other's needs and endeavours. Universities are 'professionalizing' themselves in order to meet society's needs, and society will be seeking competent professionals among European university graduates.

\section{References}

ANECA. Encuesta de inserción laboral [Survey on Integration into Working Life]. Madrid:

Omán, 2004a.

ANECA. Título de grado en Pedagogía y Educación Social [Degree in Social Education and Teaching] Vol. 1-2. Madrid, Omán, 2004b.

BRENNAN, J. and MCGEEVOR, Ph. CNAA Graduates: Their Employment and Their Experience after Leaving College. London: CNAA, 1987. 
CABRERA, A. F., WEERTS, D. J. and BRADFORD, J. Z. "Encuestas a egresados; tres fundamentos conceptuales en el seguimiento de egresados universitarios" [Graduate Surveys: Three Conceptual Bases in Monitoring University Graduates], in J. Vidal, ed. Métodos de análisis de la inserción laboral de los universitarios [Methods of Analysing Graduate Employment]. Salamanca: MEC, 2003, pp. 55-80.

CASAL, J., MASJUAN, J. M. and PLANAS, C. La inserción social y profesional de los jóvenes [Social Integration and Employment of Young People]. Madrid: CIDE, 1991.

CONSEJO DE UNIVERSIDADES. Plan Nacional de Evaluación de la Calidad de las Universidades. Informe anual de la segunda Convocatoria [National Plan to Assess the Quality of Universities. Annual Report on the Second Meeting]. Madrid: MEC, 2002.

CUADRADO, J. R. and IGLESIAS, C. Cambio sectorial y desempleo en España [Sectoral Change and Unemployment in Spain]. Bilbao: Fundación BBVA, 2003.

FIGUERA, P. La inserción del universitario en el mercado de trabajo [Integration of Graduates in the Labour Market]. Barcelona: EUB, 1996.

GONZALEZ, J. and WAGENAAR, R. "An Introduction: Tuning Educational Structures in Europe". I La contribución de las universidades al proceso de Bologna [The Contribution of the Universities to the Bologna Process]. Bilbao: Universidad de Deusto. Retrieved 11 May PROFESSIONALIZATION IN UNIVERSITIES AND EUROPEAN CONVERGENCE 409 2008, from <http://tuning.unideusto.org/tuningeu/images/stories/template/General_Brochure_ Spanish_version.pdf>, 2006.

GARCÍA MONTALVO, J., PEIRÓ, J. M. and SORO, A. Observatorio de la inserción laboral de los jóvenes [Monitoring Centre for Employment of Young People]. Madrid: Capital Humano, 2003.

IZQUIERDO, F. and GONZALEZ, R. M. La calidad de la enseñanza superior y otros temas universitarios [The Quality of Higher Education and Other University Issues]. Madrid: Universidad Politécnica de Madrid, 1994.

LATIESA, M., NUÑEZ, J. and MARTINEZ, R. Políticas y Sociología: ámbitos académico y laboral [Politics and Sociology: Academic and Labour Spheres]. Granada: Universidad de Granada, 2001.

MARTINEZ, R. La inserción laboral de los universitarios. Granada: Universidad de Granada, 2002. 
MOLERO, D. "Situación laboral de los gradiados universitarios, necesidades y demandas de formación. Una propuesta de actuación", in J. Ruiz and G. Medina, eds. Orientación educative e intervención psicopedagógica. I Jornadas andaluzas de orientatción y psicopedagogía. Jaen: Publicaciones de la Universidad de Jaen, 2000, pp. 375-386.

RODRIGUEZ, S. and PRADES, M. "La evaluación de la transición al mercado laboral de las universidades catalanas" [Assessment of the Transition from Catalan Universities to the Labour Market], in J. Vidal, coord. Métodos de análisis de la inserción laboral de los titulados universitarios [Methods of Analysing Graduate Employment]. Salamanca: MEC, 2003.

RUIZ, J. and MOLERO, D. “La inserción laboral de los titulados universitarios dentro de un plan global para la mejora de la calidad en la universidad", Bordón 541 (2002): 15 1-183.

VIDAL GARCIA, J. Métodos de análisis de la inserción laboral de los universitarios [Methods of Analysing Graduate Employment]. Salamanca: MEC, 2003 